\title{
Fluoxetine does not Impair Motor Function in Patients With Parkinson's Disease: Correlation between Mood and Motor Functions with Plasma Concentrations of Fluoxetine/Norfluoxetine
}

\author{
Eleonora Džoljić* and Vladimir Kostić \\ Faculty of Medicine, University of Belgrade, Serbia
}

Submission: November 07, 2016; Published: January 13, 2017

*Corresponding author: Eleonora Dzoljic, Specialist in neurology and clinical pharmacology, Senior Research Fellow, Clinic of Neurology, Clinical Centre of Serbia, Faculty of Medicine University of Belgrade, Dr Subotica 6, 1100 Belgrade, Serbia, Tel: (381) 11 3064222; Fax: (381) 11 2684577; Email: dr.elidz@gmail.com

\begin{abstract}
Objective: Selective serotonin reuptake inhibitors are the most commonly chosen antidepressants in patients with Parkinson's disease (PD). The aim of our study was to assess the influence of fluoxetine (Flu) on motor functions in patients with PD.

Methods: In this prospective, controlled, open-label study, 18 patients with PD and mild depression $(10 \leq \mathrm{HDRS} \leq 23$,) without dementia ( $25 \leq$ MMSE) were treated with Flu. Both single and repeated dose effects of Flu were assessed on days 1-50. Plasma concentrations of Flu and norfluoxetine (NORFlu) were correlated with the results of selected motor function performance scores (UPDRS-motor score, FTT and PPT). Severity of PD, depression and dementia were evaluated using standard tests (HY, ADL, HDRS, MMSE).

Results: Steady-state for Flu/NORFlu was reached after 18 days of treatment. Such a plateau correlated with significant improvements in both scores of depression and Parkinson's disability (HDRS, UPDRS and ADL, respectively). In addition, FTT and PPT scores also increased until day 18, with further slight fluctuations around the plateau. Optimal motor performances correlated with Flu concentrations of approx. 60-110 microg/L.

Conclusion: Flu (20 mg/day) significantly reduced depression in PD patients while it did not impair their motor performances. Because substantial placebo effects may arise in studies of PD and depression, large, prospective, randomized, placebo-controlled clinical trials are warranted.
\end{abstract}

Keywords: Parkinson's disease; Motor function tests; Plasma concentrations of fluoxetine/norfluoxetine

\section{Introduction}

Depression is the most common and frequently disabling psychiatric condition in patients with Parkinson's disease (PD). Prevalence of depression in patients with PD varies from 7-76\% depending on the assessment method [1]. Such a depression is mostly persistent or recurrent. It may be accompanied with anxiety, cognitive impairment and may reduce effectiveness of antiparkinson's therapy [2-5]. The depression increases PD patients' disability and significantly reduces their quality of life. Consequently, approximately $50 \%$ of patients with PD receive antidepressant therapy [4-7].

The optimal treatment for depression in PD patients has not been established. Several antidepressants were tested in randomized clinical trials without sufficient statistical power (e.g. citalopram, sertraline, fluoxetine, amitriptyline and nortriptyline). Amitriptyline seems to be more effective than fluoxetine in PD patients with severe depression. However, it is not necessarily the first choice for treatment of depression in PD patients, according to the recommendations of the American Academy of Neurology [8]. In addition, the adverse effects of amitriptyline such as orthostatic hypotension, sedation, cognitive and anticholinergic effects might preclude its use and increase the dropout rate in parkinsonians $[1,9,10]$.

On the other hand, selective serotonin reuptake inhibitors (SSRIs) are used as a first line treatment of depression 51\% of the time $[1,9,10]$. In postmortem studies of patients with PD depletion of 5-HT in the caudate as well as hypothalamus and frontal cortex was reported [11-14], with preferential loss of 5 -HT in the caudate compared with the putamen, but with relatively less loss of 5-HT (66\%) than dopamine (98\%) [15]. 


\section{Open Access Journal of Neurology \& Neurosurgery}

Imaging studies in vivo have also suggested depletion of 5-HT innervation to the striatum as measured via decreased 5-HT transporter binding [16-18]. The loss of striatal 5-HT in PD may be secondary to neurodegeneration within the raphe nuclei as Lewy bodies are seen in the raphe nuclei $[19,20]$, associated with cell loss [21,22]. Taucher et al. [23] were the first to demonstrate the pharmacodynamic action of the selective 5-HT transporter blocker fluoxetine in the human brain in vivo [23]. Meyer et al. [24] showed that 80\% 5-HT transporter occupancy was achievable with SSRI at therapeutic doses in a study in patients with mood and anxiety disorders [24]. Apart from these drug-effects studies, it has been showed that recovery of central serotonergic system after SSRI therapy was associated with reduction of clinical symptoms in 18 depressive subjects using [123I]-CIT and SPECT [25]. All these findings of SSRIs5-HT transporter occupancy in PET/SPECT studies clearly reflect the pharmacologically induced changes in serotonergic transmission $[5,26]$.

However, data on the efficacy and safety of SSRIs in PD are still lacking and sufficiently large scale randomised controlled trials are required. Although the introduction of SSRIs offers new opportunities for the treatment of depression in PD, these agents could produce extrapyramidal adverse reactions aggravating parkinsonism $[1,10]$. While epidemiological studies have not suggested increased risk of worsening PD when SSRIs have been prescribed for depression [27], almost one hundred detailed reports on extrapyramidal adverse effects linked to SSRIs antidepressants have been published [28,29].

The influence of Flu on motor performances in PD patients still remains to be clarified. Extrapiramidal side effects of Flu seem to be related to the exacerbation of Parkinson's disability [30]. However, it was also reported that Flu did not increase Parkinson's disability either in retrospective [31] or in prospective studies [32]. Therefore, the authors argue for more systemic and controlled research examining the treatment of depression in patients with PD [1,33,34].

The aim of this study was to investigate motor performances of PD patients treated with antidepressant Flu and to assess a possible correlation between mood and motor performance scores with plasma concentrations of Flu and its active metabolite, norfluoxetine (NORFlu).

\section{Methods}

Efficacy and tolerability of Flu was assessed in the prospective, 80 days, controlled, open-label clinical trial, with blind assessment. Flu was administered to 18 patients with nonfluctuating PD in the early Hoehn and Yahr stages (HY), I and II [35], accompanied with mild depression (Hamilton Rating Scale for Depression: $10 \leq$ HDRS $\leq 23$ ), without dementia (Mini Mental State Examination: MMSE < 25). These 18 patients were either

A. de novo PD patients (PD0 group, $N=9$ ), or

B. PD patients who were on the stable antiparkinsonian treatment (PDt group, $\mathrm{N}=9$ ), without selegiline, rasagiline and/or dopamine agonists for at least two months prior to Flu.

Patients with secondary parkinsonism, those with the MMSE score $<25$ [36], history of stroke, neurological disorder other than PD, or any concomitant serious medical illness, and drug toxicity causing hallucinations, confusional episodes or delirium, were not included in the study. During the study, patients were not allowed to use neuroleptics, sedatives, hypnotics or other antidepressants, as well as drugs with potential extrapyramidal adverse effects. The study has been approved by the Ethical Committee of the Faculty of Medicine, University of Belgrade, Serbia. Before entering the study patients gave written informed consent.

All the patients were treated with two consecutive dosing regimens:

\section{First acute treatment with flu}

First day, patients received Flu, $20 \mathrm{mg}$ per day, at 8 a.m. Evaluation of motor performances and blood sampling for Flu/ NORFlu plasma concentration measurement were carried out immediately before the Flu treatment (day 1, 0 h), and $4 \mathrm{~h}, 6$ $\mathrm{h}$ and $8 \mathrm{~h}$ after the administration of the drug. Flu was than withdrawn for three consecutive days. On the fifth day, patients received $40 \mathrm{mg}$ of Flu at $8 \mathrm{a}$.m. and all the tests and blood sampling were repeated in the same order (day 5, 0-8 h after the administration of the drug). The pattern of blood sampling depends on Tmax for Flu, ranging from 4 to 8 hours after the single dose administration [37] (Figure 1, panel A).
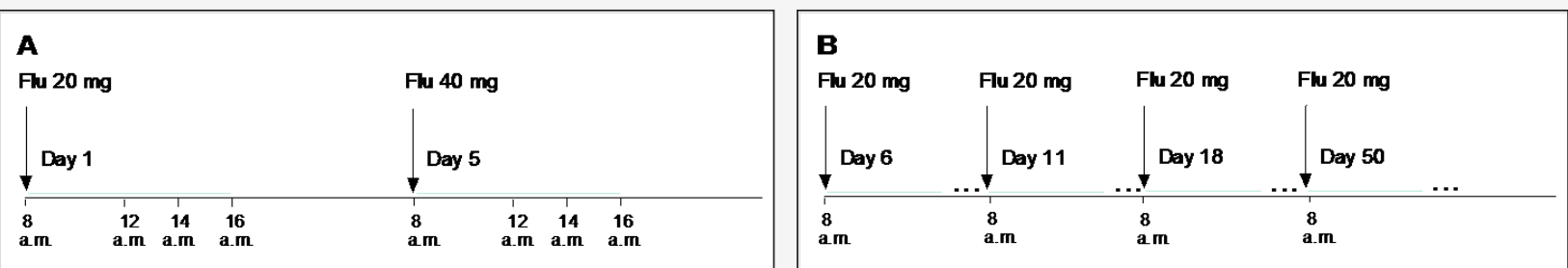

Figure 1: Design of the study: acute and chronic treatment of parkinsonian patients with Flu (panels A and B, respectively). 


\section{Open Access Journal of Neurology \& Neurosurgery}

\section{Second, chronic treatment with flu}

In the same patients, regular Flu treatment was initiated ( $20 \mathrm{mg}$ per day, at 8 a.m.) on day 6 after the beginning of such a therapy, and the motor performances were evaluated on days 11 , 18, 50, and 80. (Steady state for Flu is reached after 18 days of Flu treatment.) (Figure 1, panel B).

All the tests were performed in 18 out of 18 patients on days 11 and 18. Afterwards, 9 out of 18 patients were tested on day 50 , and 8 out of 18 patients on day 80 (dropout rates of $50 \%$ and $44 \%$, respectively).

Two blinded refers evaluated severity of motor impairment using the Unified Parkinson's Disease Rating Scale (UPDRS-motor score, [38]), ADL (Schwab and England Activities of Daily Living Score) and computerized version of the quantitative motor test Finger Tapping Test (FTT, [39]) and the Purdue Pegboard Test (PPT, [40]). The current severity of depression was evaluated using the 17-item Hamilton Rating Scale for Depression (HDRS, [41]).

Bioanalytical method used for determination of plasma Flu and NORFlu concentrations was high performance liquid chromatography (HPLC) coupled with mass spectrometry (MS). The method used liquid chromatograph Therm Separation Products Spectra System (Autosampler AS3000, HPLC binary pump P2000, Degasser SCM1000), mass spectrometer with electro spray ionization source (Finnigan MAT SSQ7000 LC/MS ESI System), Computer Digital UNIX Alpha Station 255. Recovery was very high, not less than $90.8 \%$ for Flu and $80.2 \%$ for NORFlu. Limit of quantification was $2.5 \mu \mathrm{g} / \mathrm{L}$ for Flu and $10 \mu \mathrm{g} / \mathrm{L}$ for NORFlu, and limit of detection was $1 \mu \mathrm{g} / \mathrm{L}$ for Flu and $5 \mu \mathrm{g} / \mathrm{L}$ for NORFlu. Correlation coefficient was 0.9993 (concentration range of $2.5-250 \mu \mathrm{g} / \mathrm{L}$ ), and 0.9989 (concentration range of 10-250 $\mu \mathrm{g} / \mathrm{L}$ ), for Flu and NORFlu, respectively. Coefficient of variation, calculated for precision, was not higher than $8.33 \%$ and $8.83 \%$ for Flu and NORFlu, respectively.

\section{Statistical analysis}

Results are expressed as the mean \pm standard error of the mean (S.E.M.) of $\mathrm{N}$ observations (descriptive statistics).
Comparisons between groups were analyzed using Fisher's exact test, t-test, and one-way analysis of variance (ANOVA), when appropriate. In addition, correlation analysis, factor analysis, extraction method (principal component analysis), rotation method (Oblimin with Kaiser normalization) and trend analysis (fitting or least square method) were used.

\section{Results}

All the patients were right-handed. Both groups, PD0 and PDt, had similar laterality of Parkinson's symptoms (affected right side/affected left side $=6 / 3$ ). Among 12/18 patients with affected right side, there was no significant difference between FTTr (FFT for right hand) and FTTl (FTT for left hand) scores, as well as between PPTr (PPT for right hand) and PPTI (PPT for left hand) scores ( $\mathrm{P}=0.66$, and 0.89 , respectively). Among 6/18 patients with affected left side, FTTr was significantly better than FTTl (P = 0.03) and PPTr was significantly better than PPTl $(P=0.02)$. In addition, only PPTr score was significantly higher for left side-affected PD patients comparing to the right sideaffected PD patients $(P=0.03)$. Age, gender and main clinical scores of PD0- and PDt-patients are shown in Tables 1 and 2.

Table 1: Baseline characteristics of patients with Parkinson's disease: group of de novo patients without antiparkinson's medication ( $\left.P D_{0}\right)$ and group with previous stable antiparkinson's therapy $\left(P D_{t}\right)$ (mean \pm S.E.M.)

\begin{tabular}{|c|c|c|c|c|c|}
\hline Group & $\begin{array}{c}\text { Age } \\
\text { (years) }\end{array}$ & $\begin{array}{c}\text { Duration } \\
\text { of PD } \\
\text { (years) }\end{array}$ & \multicolumn{2}{|c|}{$\begin{array}{c}\text { Previous Levodopa } \\
\text { Therapy }\end{array}$} & \\
\hline & & & Duration & Dose & \\
\hline & & (years) & (mg/day) & \\
\hline $\begin{array}{c}\text { PD0 (N } \\
\text { 9) }\end{array}$ & $\begin{array}{c}55.7 \pm \\
3.0\end{array}$ & $2.7 \pm 0.9$ & 0 & 0 & $\begin{array}{c}28.0 \pm \\
0.6\end{array}$ \\
\hline $\begin{array}{c}\text { PDt (N } \\
=9 \text { ) }\end{array}$ & $\begin{array}{c}56.0 \pm \\
2.7\end{array}$ & $3.6 \pm 1.1$ & $3.9 \pm 0.9$ & $\begin{array}{c}458.3 \pm \\
55.1\end{array}$ & $\begin{array}{c}27.9 \pm \\
0.9\end{array}$ \\
\hline
\end{tabular}

PD - Parkinson's disease; MMSE - Mini Mental State Examination.

Depressive symptoms were similarly reduced after 18 days of Flu treatment in both PD0 and PDt patients (Table 2, HDRS scores, $\mathrm{P}<0.05)$. At the same time, Parkinson's disability was remarkably improved, especially in PDt patients (Table 2, UPDRS and ADL, $\mathrm{P}<0.05$, both).

Table 2: Staging of Parkinson's disease: group of patients without antiparkinson's medication $\left(\mathrm{PD}_{0}\right)$ and group of patients with stable antiparkinson's therapy $\left(\mathrm{PD}_{\mathrm{t}}\right)$, before (day 0 ) and on the 18th day of Flu medication (day $18, \approx$ steady state for Flu) $(\mathrm{mean} \pm \mathrm{S}$.E.M.)

\begin{tabular}{|c|c|c|c|c|c|c|c|c|c|}
\hline \multicolumn{2}{|c|}{ Days of Flu treatment } & \multicolumn{3}{|c|}{ Day 1} & \multicolumn{5}{|c|}{ Day 5} \\
\hline Parameter & Group & $0 \mathrm{~h}$ & $4 \mathrm{~h}$ & $6 \mathrm{~h}$ & $8 \mathrm{~h}$ & $0 \mathrm{~h}$ & $4 \mathrm{~h}$ & $6 \mathrm{~h}$ & $8 \mathrm{~h}$ \\
\hline \multirow[t]{2}{*}{ Cflu $(\mu \mathrm{g} / \mathrm{l})$} & PD0 & 0 & $9.58 \pm 1.51$ & $11.44 \pm 1.31$ & $14.80 \pm 0.80$ & $3.24 \pm 1.51$ & $19.98 \pm 3.30$ & $\begin{array}{c}23.19 \pm \\
1.89\end{array}$ & $27.40 \pm 2.06$ \\
\hline & PDt & 0 & $8.83 \pm 1.02$ & $14.76 \pm 1.88$ & $16.99 \pm 2.28$ & $5.87 \pm 1.40$ & $22.71 \pm 3.39$ & $\begin{array}{c}25.60 \pm \\
3.90\end{array}$ & $33.62 \pm 2.87$ \\
\hline \multirow[t]{2}{*}{$\begin{array}{c}\text { CNORFlu } \\
(\mu \mathrm{g} / \mathrm{l})\end{array}$} & PD0 & 0 & 0 & 0 & 0 & 0 & $3.57 \pm 1.78$ & $7.48 \pm 1.78^{*}$ & $10.48 \pm 1.46$ \\
\hline & PDt & 0 & 0 & 0 & 0 & $2.57 \pm 1.71$ & $7.72 \pm 2.02$ & $\begin{array}{c}11.95 \pm \\
0.48\end{array}$ & $12.87 \pm 0.49$ \\
\hline
\end{tabular}




\section{Open Access Journal of Neurology \& Neurosurgery}

A. Acute treatment with Flu: there were no remarkable changes in motor function scores (FTT, PPT) after the administration of $20 \mathrm{mg}$ of Flu (day 1), or $40 \mathrm{mg}$ of Flu (day
5) (Table 3). Groups PD0 and PDt differ only in FTTr scores at $0 \mathrm{~h}$ and $8 \mathrm{~h}$ after the administration of $40 \mathrm{mg}$ of Flu (day $5)$.

Table 3: Changes in Flu and NORFlu concentrations, and motor function scores (FTT, PPT) during acute treatment with Flu (day 1: $20 \mathrm{mg}$; day 5: $40 \mathrm{mg}$ ) (mean \pm S.E.M.).

\begin{tabular}{|c|c|c|c|c|c|c|c|c|c|}
\hline \multicolumn{2}{|c|}{ Days of Flu treatment } & \multicolumn{3}{|c|}{ Day 1} & \multicolumn{5}{|c|}{ Day 5} \\
\hline Parameter & Group & $\mathbf{O} \mathbf{h}$ & $4 \mathrm{~h}$ & $6 \mathrm{~h}$ & $8 \mathrm{~h}$ & $\mathbf{O} \mathbf{h}$ & $4 \mathrm{~h}$ & $6 \mathrm{~h}$ & 8 h \\
\hline \multirow{2}{*}{ Cflu $(\mu \mathrm{g} / \mathrm{l})$} & $\mathrm{PD}_{0}$ & 0 & $9.58 \pm 1.51$ & $11.44 \pm 1.31$ & $14.80 \pm 0.80$ & $3.24 \pm 1.51$ & $19.98 \pm 3.30$ & $23.19 \pm 1.89$ & $27.40 \pm 2.06$ \\
\hline & $\mathrm{PD}_{\mathrm{t}}$ & 0 & $8.83 \pm 1.02$ & $14.76 \pm 1.88$ & $16.99 \pm 2.28$ & $5.87 \pm 1.40$ & $22.71 \pm 3.39$ & $25.60 \pm 3.90$ & $33.62 \pm 2.87$ \\
\hline \multirow{2}{*}{$\begin{array}{l}\text { CNORFlu } \\
(\mu \mathrm{g} / \mathrm{l})\end{array}$} & $\mathrm{PD}_{0}$ & 0 & 0 & 0 & 0 & 0 & $3.57 \pm 1.78$ & $7.48 \pm 1.78^{*}$ & $10.48 \pm 1.46$ \\
\hline & $\mathrm{PD}_{\mathrm{t}}$ & 0 & 0 & 0 & 0 & $2.57 \pm 1.71$ & $7.72 \pm 2.02$ & $11.95 \pm 0.48$ & $12.87 \pm 0.49$ \\
\hline \multirow{2}{*}{ FTTr } & $\mathrm{PD}_{0}$ & $5.11 \pm 0.40$ & $4.91 \pm 0.45$ & $5.20 \pm 0.35$ & $5.01 \pm 0.43$ & $5.44 \pm 0.24^{*}$ & $5.31 \pm 0.28$ & $5.19 \pm 0.31$ & $5.44 \pm 0.30^{*}$ \\
\hline & $\mathrm{PD}_{\mathrm{t}}$ & $3.60 \pm 0.53$ & $3.55 \pm 0.47$ & $3.93 \pm 0.43$ & $4.14 \pm 0.48$ & $4.17 \pm 0.44$ & $4.16 \pm 0.45$ & $4.36 \pm 0.43$ & $4.16 \pm 0.44$ \\
\hline \multirow{2}{*}{ FTTl } & $\mathrm{PD}_{0}$ & $4.25 \pm 0.41$ & $4.34 \pm 0.36$ & $4.56 \pm 0.36$ & $4.57 \pm 0.31$ & $4.42 \pm 0.24$ & $4.46 \pm 0.32$ & $4.49 \pm 0.32$ & $4.83 \pm 0.41$ \\
\hline & $\mathrm{PD}_{\mathrm{t}}$ & $4.00 \pm 0.49$ & $4.05 \pm 0.40$ & $4.12 \pm 0.46$ & $4.10 \pm 0.46$ & $4.21 \pm 0.45$ & $4.24 \pm 0.42$ & $4.15 \pm 0.42$ & $4.38 \pm 0.40$ \\
\hline \multirow{2}{*}{ PPTr } & $\mathrm{PD}_{0}$ & $10.33 \pm 0.93$ & $11.56 \pm 0.96$ & $11.56 \pm 1.07$ & $11.22 \pm 0.85$ & $11.33 \pm 0.94$ & $12.22 \pm 0.81$ & $11.78 \pm 0.98$ & $11.89 \pm 0.92$ \\
\hline & $\mathrm{PD}_{\mathrm{t}}$ & $11.22 \pm 1.10$ & $11.56 \pm 1.10$ & $11.44 \pm 1.09$ & $11.78 \pm 1.15$ & $11.44 \pm 1.08$ & $11.67 \pm 1.24$ & $11.00 \pm 1.27$ & $10.89 \pm 1.27$ \\
\hline \multirow{2}{*}{ PPTl } & $\mathrm{PD}_{0}$ & $9.22 \pm 0.66$ & $9.89 \pm 0.66$ & $10.67 \pm 0.67$ & $10.44 \pm 0.67$ & $10.44 \pm 0.75$ & $10.67 \pm 0.78$ & $10.78 \pm 0.88$ & $10.33 \pm 0.87$ \\
\hline & $\mathrm{PD}_{\mathrm{t}}$ & $11.22 \pm 0.91$ & $11.89 \pm 1.32$ & $10.78 \pm 1.28$ & $12.00 \pm 1.18$ & $12.00 \pm 1.12$ & $12.00 \pm 1.30$ & $11.78 \pm 1.27$ & $11.44 \pm 1.16$ \\
\hline
\end{tabular}

PD-Parkinson's disease; $\mathrm{PD}_{0}$ - de novo PD patients; $\mathrm{PD}_{\mathrm{t}}$ - PD patients with stable antiparkinson's therapy; $\mathrm{C}_{\mathrm{Flu}}$, $\mathrm{C}_{\mathrm{NORFIu}}-$ plasma concentrations of fluoxetine and norfluoxetine; FTTr, FTTI - Finger Tapping Test for left and right hand; PPTr, PPTI - "Purdue Pegboard Test for left and right hand; * $-\mathrm{P}<0.05, \mathrm{PD}_{0}$ vs. $\mathrm{PD}_{\mathrm{t}}$.

B. Chronic treatment with Flu: $(20 \mathrm{mg} /$ day, 80 days $)$ : plasma concentrations of Flu and NORFlu increased in a time-related manner (CFlu, and CNORFlu, respectively) (Figure 2). Table 4 shows plasma concentrations of Flu and NORFlu as well as motor performance scores for the each group assessed during chronic treatment with Flu.
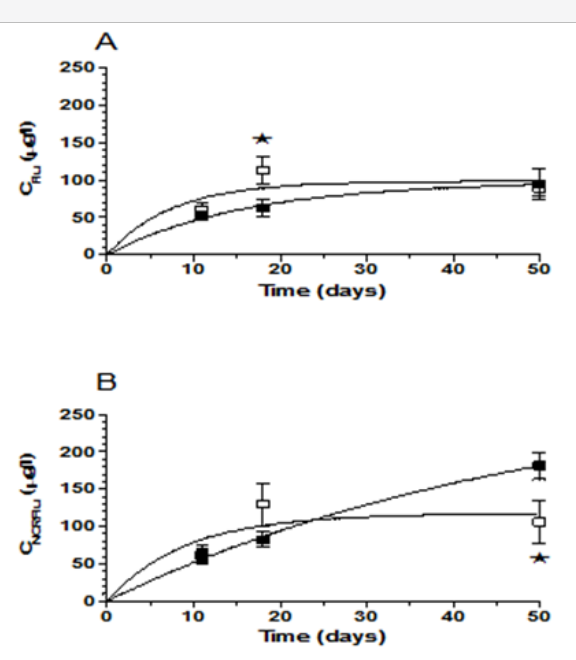

Figure 2: Changes of plasma concentrations of fluoxetine $\left(\mathrm{C}_{\mathrm{Flu}}\right)$ and its active metabolite norfluoxetine (CNORFlu) over time (panels $A$ and $B$, respecively) in $P_{D O}(c)$ and $P_{D t}$ patients ( $(\square)$, during chronic treatment with Flu (days 11-80, $20 \mathrm{mg} /$ day). Each point represents the mean \pm S.E.M. of plasma concentrations obtained from 9 separate $P_{D 0}$ or $P_{D t}$ patients. ${ }^{*} P<0.05, P_{D 0}$ vs. $P_{D t}$ group.
Different patterns of changes were observed in PD0 and PDt patients. In the former case, a sustained increase in both CFlu, and CNORFlu was observed until day 18, i.e. the plateau was reached after 18 days of treatment. In the latter case, plasma concentrations continuously raised until the end of the observation period (day 50) (Table 4). CFlu were significantly higher in PD0 than in PDt group after 18 days of treatment (Figure 2, Table 4).

During chronic treatment with Flu, FTTr scores in PD0 group were continuously higher than in PDt group, reaching the significance on days 11 and 50 ( $\mathrm{P}=0.03$ and 0.04 , respectively) (Table 4). Such a difference was less pronounced regarding FTTl, PPTr and PPTl scores, never reaching statistical significance. Of note, the raise in CFlu between days 0 and 18 (the plateau) coincided with the increase in FTT and especially in PPT scores (Tables 3 and 4).

Factor analysis reveals that influence of Flu/NORFlu concentrations increases over time (cummulative data from both PD0 and PDt patients; plasma samples were taken on days $0,5,11$, and 18 , six hours after Flu administration). The variance explained by the concentrations of Flu and NORFlu permanently increases from $13.9 \%$ (day 5) to $29.9 \%$ (day 11 ) and $37,6 \%$ (day 18) of cumulative variance (values of $89.4 \%, 84.9 \%$ and $91.8 \%$, respectively). At the same time, influence of motor function scores decreases over time: variance explained by PPT and FTT scores of $75.5 \%, 55 \%$, and $54.1 \%$ (days 5, 11, and 18, respectively). PPT and FTT scores significantly correlated on day $11(\mathrm{r}=0.62 ; \mathrm{P}<0.01)$. In addition, an inverse correlation was 
found between Flu/NORFlu concentrations and PPT-, but not with FTT scores, on day $18(r=-0.70$ and 0.48 , respectively).

Gastrointestinal, cardiovascular side effects and/or insomnia, somnolence and excessive daytime sleepness as adverse reactions of Flu were not reported in the PD patients considered in the study.

\section{Discussion}

Main results of our pilot study show that Flu treatment may alleviate depression in PD patients without deterioration of motor function scores. FTT, PPT and UPDRS-motor scores were even improved despite the parallel increase in plasma concentrations of Flu/NORFlu during first 18 days of the study.

Depression in PD must be properly diagnosed and treated [42]. However, rare reports on the use of various antidepressants in PD patients offer controversial data on their safety regarding motor adverse reactions. Controlled clinical studies confirming the efficacy of Flu in PD patiens and assessing the risk-benefit ratio of such a therapy are still lacking [43].

The broad therapeutic window for Flu is due to its highly variable pharmacokinetics [5,44-46]. Flu steady state is achieved approximately after 3 weeks (concentrations of approx. 110 $\mu \mathrm{g} / \mathrm{L}$ ). If plasma concentrations increase above $110 \mu \mathrm{g} / \mathrm{L}$, the dosage should be adjusted accordingly. Factor analyses indicates that mean Flu concentrations of approx. 60-110 $\mu \mathrm{g} / \mathrm{L}$ have the most powerful effect on both PPT and FTT scores, which were significantly improved within that concentration range.

PPT and FTT are quantitative motor tests. While FTT more reflects motor speed, PPT is test for fine motor functions and coordination $[40,47]$. Since all our patients were right-handed only among 6/18 patients with affected left side FTTr and PPT $r$ were better than FTTl and PPTl, respectively, pointing to more efficient compensatory mechanisms in dominant hand $[48,49]$.

The pharmacological profile of fluoxetine is unique among the antidepressants used in PD patients. Fluoxetine is both SSRI agent and a 5HT2C antagonist [50]. Recent investigation confirmed that 5HT1A agonists and 5HT2C antagonists could be important features in treatment of PD. In particular, 5HT2c receptors seem to tonically inhibit dopamine release from all three major dopaminergic pathways. Accordingly, 5HT2c antagonists could block such an inhibiton, especially in the terminal regions of the nigrostriatal and mesolimbic pathways [51].

Additionally, 5-HT2c receptors are selectively located within the substantia nigra pars reticulata $(\mathrm{SNr})$ and medial globus pallidus (GPm) and 5-HT via 5-HT2c receptors is excitatory in the SNr [52-55], which may contribute to the increased activity of these regions in PD. Systemic administration of selective 5-HT2c antagonists to 6-hydroxydopamine-lesioned rodents potentates the antiparkinsonian action of dopamine D1 and D2 agonists
[56,57], which is an action mediated via 5-HT2c receptors in the SNr [56]. Thus, 5-HT2c receptor antagonists may improve parkinsonism and drugs with 5-HT2c receptor antagonist action, such as fluoxetine, are unlikely to worsen PD [57].

The pathophysiological mechanisms involved in mood disturbances in PD remain complex. Serotonergic dysfunction has been postulated as such systems are involved in mood disorders in non-PD and the raphe nuclei, as well as hippocampus and prefrontal cortex, appear to be the primary sites affected $[58,59]$. Moreover, transcranial ultrasound studies have suggested an association with reduced brainstem raphe echogenicity and nigral hyperechogenicity in patients with depression preceding PD onset compared with nondepressed patients with PD [60]. As the PD disease progress, Lewy bodies occur with the rostral raphe, thalamus and limbic and cortical regions [15-22,61], which may result in the mediating of mood disturbances in PD [23-26].

In depression associated with PD, PD-specific pathology, with multiple transmitter deficiencies in mesocortical monoaminergic systems, plays a major role. This includes the mesocorticolimbic dopaminergic projection as well as mesocortical noradrenergic and serotonergic projections. Corticolimbic noradrenergic denervation through cell loss in the locus coeruleus and serotonergic deneravtion via serotonergic cell loss in the raphe nucleus are also likely to be important [1115,22-26,62]. Postmortem evidence has shown a lower density of neurons in the dorsal raphe nuclei in depressed versus nondepressed patients with PD [22] and cerebro-spinal fluid measurement in vivo have shown reduced serotonin metabolite (5-HIAA) levels in depressed patients with PD [63].

A [11C]-DASB PET study in seven patients with PD with untreated depression showed elevated serotonin transporter binding in the prefrontal cortex compared with non-PDmatched controls [64]. Recently, Politis et al. [65] has reported that the patients with PD with the highest scores for depressive symptoms showed significantly increased [11C]-DSAB binding in the amigdala, hypothalamus, caudal raphe nuclei and posterior cingytlate cortex compared with those patients with low depression scores, though not compared with healthy controls. The [11C]-DSAB binding values in other regions, including the anterior cingulate cortex, caudate, insula, prefrontal cortex, putamen rostral raphe nuclei, thalamus and ventral striatum, were similarly decreased in patients with PD, irrespective of their depressive symptoms scores, compared with the healthy controls. This study demonstrates that depressive symptoms in antidepressant-naïve patients with PD are associated with relatively higher serotonin binding in raphe nuclei and limbic structures. The relative increase in serotonin transporter binding in these regions could reflect either lower extracellular serotonin levels or a disease-related loss of presinaptic serotonergic neurotransmission in contributing to the pathophysiology of PD depression $[62,65]$. 


\section{Open Access Journal of Neurology \& Neurosurgery}

The phenomenology of depression in PD is also different from that in patints with non-PD with less anhedonia and feeling of guilt [66]. While aetiology of depression in Parkinson's disease is unclear (biochemical changes, psychosocial factors and situational stressors have all been implicated), it has an adverse effect on the quality of patients' lives and doctors should ensure that it is diagnosed and properly treated $[1,4,5,67]$.

Therefore, along with improvement on parkinsonian quality of life due to antidepressant activity of SSRI, symptoms such as bradikinesia, hypomima, hypophonia that overlap between depression and parkinsonism could ameliorate because an improvement of mood symptms $[1,9,10]$. Evenmore, Suzuku et al. [68] suggested that SSRIs such as fluoxetine potentially are therapeutic drugs for non-motor symptoms as well as motor symptoms in patients with PD, since fluoxetine can reverse the downregulation of cell proliferation in the subgranular zone by the unilateral 6-hydroxydopamine lesion.

Table 4: Changes in Flu and NORFlu concentrations, and motor function scores (FTT, PPT) during chronic treatment with Flu (days 11-80: 20 $\mathrm{mg} /$ day) (mean \pm S.E.M.)

\begin{tabular}{|c|c|c|c|c|}
\hline \multicolumn{2}{|c|}{ Days of Flu treatment } & Day 11 & Day 18 & Day 50 \\
\hline Parameter & Group & & & $87.99 \pm 9.88$ \\
\hline \multirow{3}{*}{ Cflu $(\mu \mathrm{g} / \mathrm{l})$} & $\mathrm{PD}_{0}$ & $60.73 \pm 7.31$ & $112.21 \pm 17.95^{*}$ & $94.13 \pm 20.54$ \\
\cline { 2 - 5 } & $\mathrm{PD}_{\mathrm{t}}$ & $51.97 \pm 6.52$ & $62.34 \pm 11.66$ & $106.51 \pm 28.73^{*}$ \\
\hline \multirow{3}{*}{ CNorFlu $(\mu \mathrm{g} / \mathrm{l})$} & $\mathrm{PD}_{0}$ & $62.17 \pm 12.29$ & $129.17 \pm 27.43$ & $181.74 \pm 18.00$ \\
\cline { 2 - 5 } & $\mathrm{PDt}$ & $60.80 \pm 9.45$ & $82.84 \pm 11.22$ & $5.34 \pm 0.45$ \\
\hline \multirow{2}{*}{ FTTr } & $\mathrm{PD}_{0}$ & $5.51 \pm 0.26^{*}$ & $5.56 \pm 0.32$ & $3.73 \pm 0.80$ \\
\hline \multirow{2}{*}{$\mathrm{FTTl}$} & $\mathrm{PD}_{\mathrm{t}}$ & $4.36 \pm 0.42$ & $4.47 \pm 0.43$ & $4.78 \pm 0.60$ \\
\cline { 2 - 5 } & $\mathrm{PD}_{0}$ & $4.62 \pm 0.35$ & $4.71 \pm 0.32$ & $4.11 \pm 0.94$ \\
\hline \multirow{2}{*}{$\mathrm{PPTr}$} & $\mathrm{PD}_{\mathrm{t}}$ & $4.27 \pm 0.40$ & $4.16 \pm 0.43$ & $14.17 \pm 0.53$ \\
\cline { 2 - 5 } & $\mathrm{PD}_{0}$ & $12.22 \pm 1.06$ & $11.83 \pm 1.08$ & $14.67 \pm 1.76$ \\
\hline \multirow{2}{*}{$\mathrm{PPTl}$} & $\mathrm{PD}_{\mathrm{t}}$ & $11.61 \pm 0.97$ & $11.44 \pm 0.90$ & $11.81 \pm 1.25$ \\
\cline { 2 - 5 } & $\mathrm{PD}_{0}$ & $12.06 \pm 1.12$ & $12.17 \pm 1.19$ & $14.50 \pm 2.08$ \\
\hline
\end{tabular}

PD-Parkinson's disease; $\mathrm{PD}_{0}$ - de novo PD patients; $\mathrm{PD}_{\mathrm{t}}-\mathrm{PD}$ patients with stable antiparkinson's therapy; $\mathrm{C}_{\mathrm{Flu}}$, $\mathrm{C}_{\mathrm{NORFlu}}$ - plasma concentrations of fluoxetine and norfluoxetine; FTTr, FTTI - Finger Tapping Test for left and right hand; PPTr, PPTI - Purdue Pegboard Test for left and right hand; * $\mathrm{P}<0.05, \mathrm{PD}_{0}$ vs. $\mathrm{PD}_{\mathrm{t}}$.

According to group of Taylor [69], depressive symptoms precede those of motor dysfunction in $12-37 \%$ of patients with PD. On the other hand, algorithms for treating depression in PD suggest that optimal antiparkinsonian treatment should precede the administration of antidepressants [1,70]. Our results support such an approach only partially: PD0 and PDt groups did not differ in their response to antidepressive therapy, while the influence of Flu on motor functions scores was not consistently related to the pretreatment with antiparkinsonian drugs. Nevertheless, successfull treatment of PD before the administration of antidepressants may diminish overlapping between depressive symptoms and core Parkinson's diasease symptoms [1].

In the present study, we failed to observe any deterioration in motor performance scores of patients with PD that was related
All these various mechanisms could explain why the improvement in Parkinson's disability scores in our patients coincided with an increase in plasma Flu and NORFlu concentrations during the first 18 days of antidepressive treatment. Another question is to assess the possible difference between PD0 and PDt patients' response to Flu treatment. The beneficial effects of Flu on motor symptoms of PD patients seem to be more pronounced in PDt group (UPDRS and ADL scores, Table 2). In addition, PPT scores were mostly higher in PDt patients during chronic treatment with Flu increasing (HDRS, Table 2). Also, the statistical significance was rarely observed between those groups regarding motor function scores; FTT values were even somewhat higher in PD0 patients on days 11 and 50 (Table 4). continuously by the end of the study (day 50). However, the antidepressive efficacy of Flu was similar in both PD groups 


\section{Open Access Journal of Neurology \& Neurosurgery}

study with paroxetine $(20 \mathrm{mg} /$ day) given to 33 nondemented depressed PD patients during 6 months, Ceravolo et al. [75] reported significant improvement of depression, as evaluated by HDRS, without influence on parkinsonian symptoms. In only one patient fully reversible worsening of tremor was observed. However, paroxetine frequently may induce tremor as an adverse effect, with a prevalence of $1 \%$ to $2 \%$. Chung et al. [76] reported that short-term paroxetine treatment did not alter the motor response to levodopa in patients with PD.

On the other hand, in two retrospective studies worsening of motor symptoms was observed in only small number of PD patients treated with SSRIs [77,78]. In a prospective study comprising 65 depressed PD out-patients treated with paroxetine (10-20 mg/day) for at least 3 months, two out of 52 patients who completed the study (3\%) experienced worsening of parkinsonian symptoms [79]. However, van de Vijver et al. [80] observed that the start of SSRI therapy in levodopa users was followed by a faster increase of antiparkinsonian drug treatment. Gony et al. [81] in recent study failed to find any significant difference in the occurrence of serious extrapyramidal symptoms between different classes of SSRI antidepressant drugs in patients with PD treated with dopaminergic antiparkinsonian drugs. According to the results of several studies $[82,83]$, including our results with Flu, it seems that the benefit of SSRIs outweigh the potential problems due to adverse effects and that they may be considered to be the rational choice in the treatment of depression in PD.

In conclusion, this pilot study suggests that Flu in a dose of $20 \mathrm{mg}$ is effective and well tolerated antidepressant in patients with Parkinson's disease. In addition, Flu improved motor function scores in PD patients and such an improvement was observed in parallel with the increase in plasma Flu and NORFlu concentrations. Also, the effects of Flu were similar in de novo PD patients and in those already treated with antiparkinsonian medications.

There are several limitations of the study: it was an openlabel study without randomization and recruited small number of patients. As with all nonradomized, open-label trials at tertiary research centres, many non-specific factors, such as relatively long duration of symptoms in de novo PD patients, may have influenced the results. However, the quantitative evaluations of motor functions using FTT and PPT significantly improved objectivity and validity of our findings. The observed dropout rates $(50 \%$ and $44 \%$ on days 50 and 80 , respectively ) are high but fit to the range observed in clinical trials in depression [84].

Therefore, our results would allow an optimal design for further large, prospective, randomized, placebo-controlled clinical trials that are necessary to evaluate the efficacy and safety of SSRI antidepressants and allow the development of evidence-based guidelines.

\section{Acknowledgment}

This work was supported by the Ministry of Science, Republic of Serbia (Project No. 175090).

\section{References}

1 Veazey C, Aki SO, Cook KF, Lai EC, Kunik ME (2005) Prevalence and treatment of depression in Parkinson's disease. J Neuropsychiatry Clin Neurosci 17(3): 310-323.

2 Kostic VS, Filipovic SR, Lecic D, Momcilovic D, Sokic D, et al. (1994) Effect of age at onset on frequency of depression in Parkinson's disease. J Neurol Neurosurg Psychiatry 57(10): 1265-1267.

3 Kostic VS, Lecic D, Filipovic SR, Stojanovic M (1995) Depression and Parkinson's disease. Psychiatriki 6: 125-135.

4 Kostic VS, Stefanova E, Dragasevic N, Potrebic S (2003) Diagnosis and treatment of depression in Parkinson's disease. In: Bedard M-A, Agid Y, Chouinard S, Fahn S, Korczyn AD, et al. (Eds.), Mental and behavioral dysfunction in movement disorders. Humana Press, Totowa, USA, pp. 351-368.

5 Hesse S, Barthel H, Schwartz J, Sabri O, Muller U (2004) Advancess in in vivo imaging of serotonergic neurons in neuropsychiatric disorders. Neurosci Biobehav Rev 28(6): 547-563.

6 Kuopio AM, Marttila RJ, Helenius H, Toivonen M, Rinne UK (2000) The quality of life in Parkinson's disease. Mov Disord 15(2): 216-223.

7 Ritter JL, Alexander B (1997) Retrospective study of selegilineantidepressant drug interactions and a review of the literature. Ann Clin Psychiatry 9(1): 7-13.

8 Miyasaki JM, Shannon K, Voon V, Ravina B, Kleiner-Fisman G, Anderson $\mathrm{K}$, et al. (2006) Practice Parameter: evaluation and treatment of depression, psychosis, and dementia in Parkinson disease (an evidence-based review): report of the Quality Standards Subcommittee of the American Academy of Neurology. Neurology 66(7): 996-1002.

9 Richard IH, Kurlan R (1997) A survey of antidepressant drug use in Parkinson's disease. Parkinson Study Group. Neurology 49(4): 11681170.

10 Vajda FJ, Solinas C (2005) Current approaches to management of depression in Parkinson's disease. J Clin Neurosci 12(7): 739-743.

11 Fahn S, Libisch LR, Cutler RW (1971) Monoamines in the human neostriatum: topographic distribution in normals and in Parkinson's disease and their role in akinesia, rigidity, chorea and tremor. J Neurol Sci 14(4): 427-455.

12 Bemheimer H, Birkmayer W, Hornykiewicz O, Jellinger K, Seitelberger F (1973) Brain dopamine and the syndromes of Parkinson and Huntigton. Clinical, morphological and neurochemical correlations. J Neurol Sci 20(4): 415-455.

13 Scatton B, Javoy-Agid F, Rouquier L, Dubois B, Agid Y (1983) Reduction of cortical dopamine, noradrenaline, serotonin and their metabolites in Parkinson' disease. Brain Res 275(2): 321-328.

14 Shannak K, Rajaput A, Rozdilsky B, Kish S, Gilbert J, et al. (1994) Noradrenaline, dopamine and serotonin levels and metabolism in the human hypothalamus: observation in Parkinson's disease and normal subjects. Brain Res 639(1): 33-41.

15 Kish SJ, Tong J, Hornykiewicz O, Rajput A, Chang LJ, et al. (2008) Preferential loss so serotonin markers in caudate versus putamen in Parkinson's disease. Brain 131(Pt 1): 120-131.

16 Kerenyl L, Ricaurte GA, Schretlen DJ (2003) Positron emission tomography of striatal serotonin tranporters in Parkinson's disease. Arch Neurol 60(9): 1223-1229. 


\section{Open Access Journal of Neurology \& Neurosurgery}

17 Guttman M, Boileau I, Warsh J, Saint-Cyr JA, Ginovart N, et al. (2007) Brain serotonin transporter binding in non-depressed patients with Parkinson's disease. Eur J Neurol 14(15): 523-528.

18 Albin RL, Koeppe RA, Bohnen NI, Wernett K, Kilbourn MA, et al. (2008) Spared caudal brainstem SERT binding in early Parkinson's disease. J Cereb Blood Flow Metab 28(3): 441-444.

19 D’Amato RJ, Zweig RM, Whitehouse PJ, Wenk GL, Singer HS, et al. (1987) Aminergic systems in Alzheimer's disease and Parkinson's disease. Ann Neurol 22(2): 229-236.

20 Braak H, Del Tredici, K, Rub U, de Vos RA (2003) Jansen Steur EN, Braak E. Staging of brain pathology related to sporadic Parkinson's disease. Neurobiol Aging 24(2): 197-211.

21 Halliday GM, Li YW, Blumbergs PC, Joh TH, Cotton RG, et al. (1990) Neuropathology of immunohistochemically identified brainstem neurons in Parkinson's disease. Ann Neurol 27(4): 373-385.

22 Paulus W, Jellinger K (1991) The neuropathologic basis of different clinical subgroups of Parkinson's disease. J Neuropathol Exp Neurol 50(6): 743-755.

23 Tauscher J, Pirker W, de Zwan M, Asenbaum S, Brucke T, et al. (1999) In vivo visualization of serotonin transporters in the human brain during fluoxetine treatment. Eur Neuropsychopharmacol 9(1-2): 177-179.

24 Meyer JH, Wilson AA, Sagrati S, Hussey D, Carella A, et al. (2004) Serotonin transporter occupancy of five selective serotonin reuptake inhibitors at different doses: an (11C) DASB positron emission tomography study. Am J Psychiatry 161(5): 826-835

25 Laasonen-Balk T, Viinamaki H, Kuikka JT, Husso-Saastamoinen M, Lehtonen J, et al. (2004) 123I- $\beta$-CIT binding and recovery from depression. A six-month follow-up study. Eur Arch Psychiatry Clin Neurosci 254(3): 152-155

26 Kostic VS, Djuricic BM, Covickovic-Sternic N, Bumbasirevic L, Nikolic M, et al. (1987) Depression and Parkinson's disease: possible role of serotonergic mechanisms. J Neurol 234(2): 94-96.

27 Arbouw ME, Movig KL, NeefC, Guchelaar HJ, Egberts TC (2007) Influence of initial use of serotonergic antidepressants on antiparkinsonian drug use in levodopa-using patients. Eur J Clin Pharmacol 63(2): 181-187.

28 Anonymous (2001) Extrapyramidal effects of SSRI antidepressants. Prescrire Int 10(54): 118-119.

29 Richard IH, Maughn A, Kurlan R (1999) Do serotonin reuptake inhibitor antidepressants worsen Parkinson's disease? A retrospective case series. Mov Disord 14(1): 155-157.

30 Leo RJ (1996) Movement disorders associated with the serotonin selective reuptake inhibitors. J Clin Psychiatry 57(10): 449-454.

31 Caley CF, Friedman JH (1992) Does fluoxetine exacerbate Parkinson's disease? J Clin Psychiatry 53(8): 278-282.

32 Dell'Agnello G, Ceravolo R, Nuti A, Bellini G, Piccinni A, et al. (2001) SSRIs do not worsen Parkinson's disease: evidence from an open-label, prospective study. Clinical Neuropharmacol 24(4): 221-227.

33 Oertel WH, Hoglinger GU, Caraceni T (2001) Depression in Parkinson's disease: an update. In: Calne D and Calne S (Eds.), Parkinson's Disease: Advances in Neurology: Parkinson's Disease. Volume 6, Lippincott Wiliams and Wikins, Philadelphia, USA, pp. 373.

34 Jankovic J and Tolosa E (2007) Depression in Parkinson's Disease and Movement Disorders. Lippincott Williams and Wilkins, Philadelphia, USA, p. 70-72

35 Hoehn MM, Yahr MD (1967) Parkinsonism: onset, progression and mortality. Neurology 17(5): 427-442.

36 Folstein MF, Folstein SE, McHugh PR (1975) "Mini-mental state". A practical method for grading the cognitive state of patients for the clinician. J Psychiatric Res 12(3): 189-198.
37 Altamura AC, Moro AR, Percudani M (1994) Clinical pharmacokinetics of fluoxetine. Clin Pharmacokinet 26(3): 201-214.

38 Fahn $\mathrm{S}$ and the members of the UPDRS Development Committee (1987) Unified Parkinson's Disease Rating Scale. In: Fahn S, Marsden CD, Goldstein M, Calne DB, editors. Recent development in Parkinson's disease. Vol II, MacMillan, Florham Park, USA, pp. 153-163.

39 Shimoyama I, Ninchoji T, Uemura K (1990) The finger-tapping test. A quantitative analysis. Arch Neurol 47(6): 681-684.

40 Lezak M (1983) Neuropsychological assessment. (2 ${ }^{\text {nd }}$ edn), Oxford University Press, New York, USA.

41 Hamilton M (1960) A rating scale for depression. J Neurol Neurosurg Psychiatry 23: 56-62.

42 Allain H, Schuck S, Mauduit N (2000) Depression in Parkinson's disease. BMJ 320(7245): 1287-1288.

43 Weintraub D, Taraborelli D, Morales KH, Duda JE, Katz IR, et al. (2006) Escitalopram for major depression in Parkinson's disease: an openlabel, flexible-dosage study. J Neuropsychiatry Clin Neurosci 18(3): 377-383.

44 Charlier C, Pinto E, Ansseau M, Plomeux G (2000) Relationship between clinical effects, serum drug concentrations and cxoncurrent drug interactions in depressed patients treated with citalopram, fluoxetine, clomipramine, paroxetine or venlafaxine. Hum Psychopharmacol 15(6): 453-459.

45 Nierenberg AA, Farabaugh AH, Alpert JE, Gordon J, Worthington JJ, et al. (2000) Timing of onset of antidepressant response with fluoxetine treatment. Am J Psychiatry 157(9): 1423- 1428.

46 Bolo NR, Hode Y, Nedelec JF, Laine E, Wagner G, et al. (2000) Brain pharmacokinetics and tissue distribution in vivo of fluvoxamine and fluoxetine by fluorine magnetic resonance. Neuropsychopharmacology 23(4): 428-438.

47 Ringendahl H (2002) Factor structure, normative data and retestreliability of a test of fine motor functions in patients with idiopathic Parkinson's disease. J Clin Exp Neuropsychol 24(4): 491-502.

48 Helmich RC, de Lange FP, Bloem BR, Toni I (2007) Cerebral compensation during motor imagery in Parkinson's disease. Neuropsychologia 11(10): 2201-2215.

49 Helmich RC, Aarts E, de Lange F, Bloem B, Toni I (2009) Increased dependence of action selection on recent motor history in Parkinson's disease. J Neurosci 29(19): 6105-6113.

50 Ni YG, Miledi R (1997) Blockage of 5HT2C serotonin receptors by fluoxetine (Prozac). Proc Natl Acad Sci U S A 94(5): 2036-2040.

51 Alex KD, Pehek EA (2007) Pharmacologic mechanisms of serotonergic regulation of dopamine neurotransmission. Pharmacol Ther 113(2): 296-320.

52 Di Matteo V, De Blasi A, Di Giulio C, Esposito E (2001) Role of 5-HT (2C) receptors in the control of central dopamine function. Trends Pharmacol Sci 22(5): 229-232.

53 Hoyer D, Pazos A, Probst A, Palacois JM (1986) Serotonin receptors in the human brain. II characterization and autoradiographic localization of 5-HT1c and 5-HT2 recognition sites. Brain Res 376(1): 97-107.

54 Invernizzi RW, Pierucci M, Calcagno E, Di Giovanni G, Di Matteo V, et al. (2007) Selective activation of 5-HT(2C) receptors stimulates GABAergic function in the rat substantia nigra pars reticulata: a combined in vivo electrophysiological and neurochemical study. Neuroscience 144(4): 1523-1535.

55 Rick CE, Stanford IM, Lacey MG (1995) Excitation of rat substantia nigra pars reticulate neurons by 5-hydroxytryptamine in vitro: evidence for a direct action mediated by 5-hydroxytryptamine $2 \mathrm{C}$ receptors. Neuroscience 69(3): 903-913. 


\section{Open Access Journal of Neurology \& Neurosurgery}

56 Fox SH, Moser B, Brotchei JM (1998) Behavioral effects of 5-HT2C receptor antagonism in the substantia nigra zona reticulate of the 6-hydroxydopamine-lesioned rat model of Parkinson's disease. Exp Neurol 151(1): 35-49.

57 Fox SH, Brotchie JM (2000) 5-HT(2c) receptor antagonist enhance the behavioral response to dopamine $\mathrm{D}(1)$ receptor agonists in the 6-hydroxydopamine-lesioned rat. Eur J Pharmacol 398(1): 59-64.

58 Drevets WC, Thase ME, Moses-Kolko EL, Price J, Frank E, et al. (2007) Serotonin-1A receptor imaging in recurrent depression: replication and literature review. Nucl Med Biol 34(7): 865-877.

59 Groenewegen HJ, Uylings HB (2000) The prefrontal cortex and the integration of sensory, limbic and autonomic information. Prog Brain Res 126: 3-28.

60 Walter U, Hoeppner J, Prudente-Morrissey L, Horowski S, Herpetz SC, et al. (2007) Parkinson's disease-like midbrain sonography abnormalities are frequent in depressive disorders. Brain 130(Pt 7): 1799-1807.

61 Braak H, DelTredici K (2008) Invited article: nervous system pathology in sporadic Parkinson's disease. Neurology 70(20): 1916-1925.

62 Seppi K (2011) Abnormal serotonergic neurotransmission contributes to the pathopysiology of depression in PD. Mov Disord 26(3): 379. doi: $10.1002 /$ mds. 23665

63 Mayeux R, Stem Y, Williams JB, Cote L, Franz A, et al. (1986) Diffent Clinical and biochemical features of depression in Parkinson's disease. Am J Psychiatry 143(6): 756-759.

64 Boileau I, Warsh JJ, Guttman M, Saint-Cyr JA, McCluskey T, et al. (2008) Elevated serotonin transporter binding in depressed patients with Parkinson's disease: a preliminary PET study with [11C]DASB. Mov Disord 23(12): 1776-1780.

65 Politis M, Wu K, Loane C, Turkheimer F.E, Molloys S, et al. (2010) Depressive symptoms in PD correlate with higher 5- HTT binding in raphe and limbic structures. Neurology 75(21): 1920-1927.

66 Ehrt U, Bronnick K, Leetjens AF, Larsen JP, Aarsland D (2006) Depressive symptom profile in Parkinon's disesse: a comparison with depressed elderly patients without Parkinson's disease. Int J Geriatr Psychiatry 21(3): 252-258.

67 Fox HN, Chuang R, Brotchei M (2009) Serotonin and Parkinson's disease on movement, mood and madness. Mov Disord 24(9): 12551266.

68 Suzuki K, Okada K, Wakuda T, Shinmura C, Kameno Y, et al. (2010) Dopaminergic neurons in the midbrain by 6-hydroxydopamine decreased hippocampal cell proliferation rate in rats: reversal by fluoxetine. PLoS One 5(2): e9260.

69 Taylor A, Saint-Cyr JA, Lang AE, Kenny FT (1986) Parkinson's disease and depression: a critical re-evaluation. Brain 109(Pt 2): 279-292.

70 Okun MS, Watts RL (2002) Depression associated with Parkinson's disease: clinical features and treatment. Neurology 58(Suppl 1): S63-S70.
71 Menza M, Marin H, Kaufman K, Mark M, Lauritano M (2004) Citalopram treatment of depression in Parkinson's disease: the impact on anxiety, disability and cognition. J Neuropsychiatry Clin Neurosci 16(3): 315319.

72 Rampello L, Chiechio S, Raffaele R, Vechio I, Nicoletti F (2002) The SSRI, citalopram, improves bradykinesia in patients with Parkinson's disease treated with L-dopa. Clin Neuropharmacol 25(1): 21-24.

73 Meara RJ, Bhowmick BK, Hobson JP (1996) An open uncontrolled study of the use of sertraline in the treatment of depression in Parkinson's disease. J Serotonin Res 2(4): 243-249.

74 Hauser RA, Zesiewicz TA (1997) Sertraline for the treatment of depression in Parkinson's disease. Mov Disord 12(5): 756-757.

75 Ceravolo R, Nuti A, Piccinni A, Dell'Agnello G, Bellini G, et al. (2000) Paroxetine in Parkinson's disease: effects on motor and depressive symptoms. Neurology 55(8): 1216-1218.

76 Chung KA, Carlson NE, Nutt JG (2005) Short-term paroxetine treatment does not alter the motor response to levodopa in PD. Neurology 64(10): 1797-1798.

77 Caley CF, Friedman JH (1992) Does fluoxetine exacerbate Parkinson's disease? J Clin Psychiatry 53(8): 278-282.

78 Richard IH, Maughn A, Kurlan R (1999) Do serotonin reuptake inhibitor worsen Parkinson's disease? A retrospective case series. Mov Disord 14(1): 155-157.

79 Tesei S, Antonini A, Canesi M, Zecchinalli A, Mariani CB, et al. (2000) Tolerability of paroxetine in Parkinson's disease: a prospective study. Mov Disord 15(5): 986-989.

80 van de Vijver DA, Roos RA, Jansen PA, Porsius AJ, de Boer A (2002) Start of a selective serotonin reuptake inhibitor (SSRI) and increase of antiparkinsonian drug treatment in patients on levodopa. Br J Clin Pharmacol 54(2): 168-170.

81 Gony M, Lapeyre-Mestre M, Montastruc JL (2003) French Network of Regional Pharmacovigilance Centers. Risk of serious extrapyramidal symptoms in patients with Parkinson's disease receiving antidepressant drugs: a pharmacoepidemiologic study comparing serotonin reuptake inhibitors and other antidepressant drugs. Clin Neuropharmacol 26(3): 142-145.

82 Tom T, Cummings JL (1998) Depression in Parkinson's disease: pharmacological characteristics and treatment. Drugs Aging 12(1): 55-74.

83 Zesiewicz TA, Gold M, Chari G, Hauser RA (1999) Current issues in depression in Parkinson's disease. Am J Geriatr Psychiatry 7(2): 110118

84 Machado M, Iskedjian M, Ruiz I, Einarson TR (2006) Remission, dropouts, and adverse drug reaction rates in major depressive disorder: a meta-analysis of head-to-head trials. Curr Med Res Opin 22(9): 1825-1837.

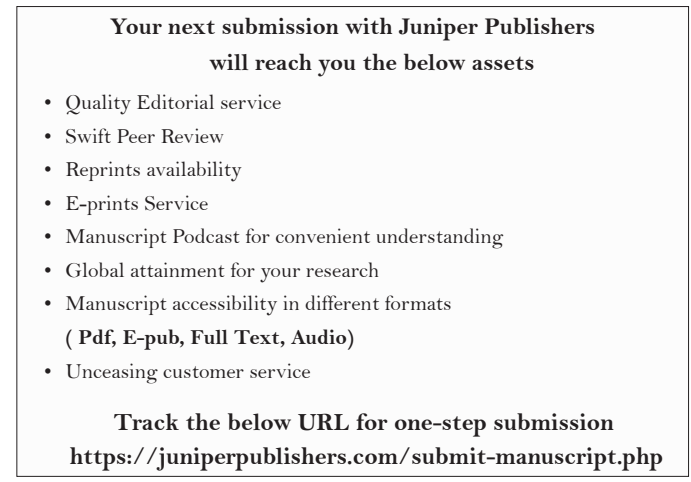

